AC 2008-2799: INTRODUCING POLYMER/CLAY NANOCOMPOSITES TO A MANUFACTURING ENGINEERING TECHNOLOGY PROGRAM

Rex Kanu, Ball State University 
AC 2008-2799: INTRODUCING POLYMER-CLAY NANOCOMPOSITES TO A MANUFACTURING ENGINEERING TECHNOLOGY PROGRAM

Rex Kanu, Ball State University, Muncie, Indiana 


\title{
INTRODUCING POLYMER-CLAY NANOCOMPOSITES TO A MANUFACTURING ENGINEERING TECHNOLOGY PROGRAM
}

\begin{abstract}
Industry and academe have shown considerable interests in polymer-clay nanocomposites (PCNs) because of the perceived benefits PCNs possess relative to traditional materials. These benefits include efficient reinforcement, thermal endurance, flame resistance, improved barrier properties, improved abrasion resistance, reduced shrinkage and residual stress, and altered electrical, electronic, and optical properties. Although these benefits are quite impressive, it is remarkable that they can be achieved with relatively low fiber/particle loadings $(2-5 \mathrm{wt} . \%)$ in a polymer matrix; a feat yet to be achieved with traditional composites where fiber/particle loadings of $10-40 \mathrm{wt}$. \% are not unusual. Consequently, nanocomposites offer, in addition to the benefits listed above, materials savings that should have favorable environmental benefits because of the implied conservative materials usage.

While traditional materials are covered in the materials courses in the manufacturing engineering technology program at Ball State University, the faculty felt it was imperative to include nanocomposite materials in our materials courses, specifically, polymer/clay nanocomposites if the program is to remain current and competitive. The approach use to expose our students to polymer nanocomposites was a combination of classroom lectures and laboratory research experiments. This paper describes the research experience of the faculty and the students with polymer-clay nanocomposites.
\end{abstract}

\section{Introduction}

Since this paper concerns the introduction of polymer-clay nanocomposites to a manufacturing engineering technology (MET) program, the author would like to begin with background information about composite materials, polymer-clay nanocomposites, and the MET program at Ball State University. This will be followed by description of a study of polymer-clay nanocomposites conducted by MET students.

Polymer-clay nanocomposite (PCN) was discovered at Toyota Central Research and Development Laboratory, Inc. in $1985^{1}$, and since its discovery, interests in PCN has grown tremendously to the extent that the number of papers on PCNs published in major journals was claimed to exceed 500 in 2005 alone ${ }^{1}$. The primary reason PCNs have generated so much interest in industry and academe is the perceived benefits that PCNs possess relative to traditional materials. These benefits include efficient reinforcement, improved stiffness (modulus of elasticity), strength, thermal endurance, flame resistance, improved barrier properties, improved abrasion resistance, reduced shrinkage and altered stress, and altered electrical, electronic, and optical properties ${ }^{2-4}$. 
Before proceeding with this paper, it may be pertinent to address the following questions in order to appreciate the nature of PCNs.

- What are composite materials?

- What are polymer-clay nanocomposites (PCNs)?

- Why polymer-clay nanocomposites (PCNs)?

What are composite materials?

Hull and Clyne ${ }^{5}$ described composite materials as materials that are often made up of a least two constituents. They suggested that in many cases, "a strong and stiff component is present, often in elongated form, embedded in a softer constituent forming the matrix." They further suggested that wood, bone, and teeth are examples of natural composite materials. Wood is made up of fibrous chains of cellulose molecules in a matrix of lignin, while bone and teeth are both essentially composed of hard inorganic crystals in a matrix of a tough organic constituent called collagen ${ }^{5}$. Agarwal and Broutman ${ }^{6}$ characterized composites as materials consisting of "one or more discontinuous phases embedded in a continuous phase. The discontinuous phase is usually harder and stronger than the continuous phase and is called the reinforcement or reinforcing material, whereas the continuous phase is termed the matrix."

From these definitions, it appears that the primary function of the reinforcing material in a composite is to absorb the excess stress or load applied to the matrix thus preventing the destruction of the matrix. The net effect is that the composite material appears stronger than the matrix. For the transfer of the excess stress to occur, there has to be interactions between the reinforcement and the matrix, otherwise the transfer of the excess stress or load from the matrix to the reinforcement would not take place. Therefore, it follows that better interactions among the constituents of composite materials would lead to improved properties of the composites.

What are polymer-clay nanocomposites (PCNs)?

The major difference between traditional polymer-fiber composites and polymer-clay nanocomposites is the size of the reinforcing fibers/nanofillers. With the traditional polymer composites, the fiber sizes are in macroscale ${ }^{6}$, that is, $10^{-6}$ meter while with PCNs, the clay particle (nanofillers) sizes are in nanoscale, that is, $10^{-9}$ meter. Because the clay particles are about three orders-of-magnitude (1000 times) smaller than the traditional filler/fibers, the interactions between the reinforcements and the matrix of PCNs are greater (therefore better) than those of traditional polymer composites. In addition, the size difference results in the clay particles having greater than aspect ratios than those of traditional fibers. The aspect ratio $(l / d)$ of a fiber is defined as the ratio of its length to its diameter.

Why polymer-clay nanocomposites (PCNs)? 
The interests in PCNs emanate from the remarkable properties they demonstrate at low filler loadings. While traditional composites require filler loadings greater than $10 \mathrm{wt} \%{ }^{6}$, PCNs filler loadings range from $2-5 \mathrm{wt} \%^{4,7}$. A reason why low filler loading are required for $\mathrm{PCN}$ is the enhanced interactions between the nanofillers and the polymer matrix brought about by the greater surface area-to-volume ratio (specific surface area) of nanofiller relative to that of traditional fillers. This difference in specific surface area is illustrated with Figure 1. The cylinders (representing fillers/fibers) in Figure 1 are assumed to have equal lengths of 9 in with the larger cylinder having a 6-in diameter while the smaller cylinders have 2-in diameters. The cross-sectional area of the larger cylinder is $9 \pi$ in $^{2}$ and it is equal to the combined cross-sectional area of the smaller cylinders. Therefore, the larger cylinder has the same volume as the combined volume of the smaller cylinders. This volume is equal to $81 \pi \mathrm{in}^{3}$. The surface area of the larger cylinder is $72 \pi$ in $^{2}$ and the combined surface area of the smaller cylinders is $180 \pi$ in $^{2}$. The specific surface area (surface area/volume) for the larger cylinder is $8 / 9 \mathrm{in}^{2} / \mathrm{in}^{3}$ and the combined specific surface area for the smaller cylinders is $20 / 9 \mathrm{in}^{2} / \mathrm{in}^{3}$. The ratio of the specific area of the larger cylinder to the combined specific
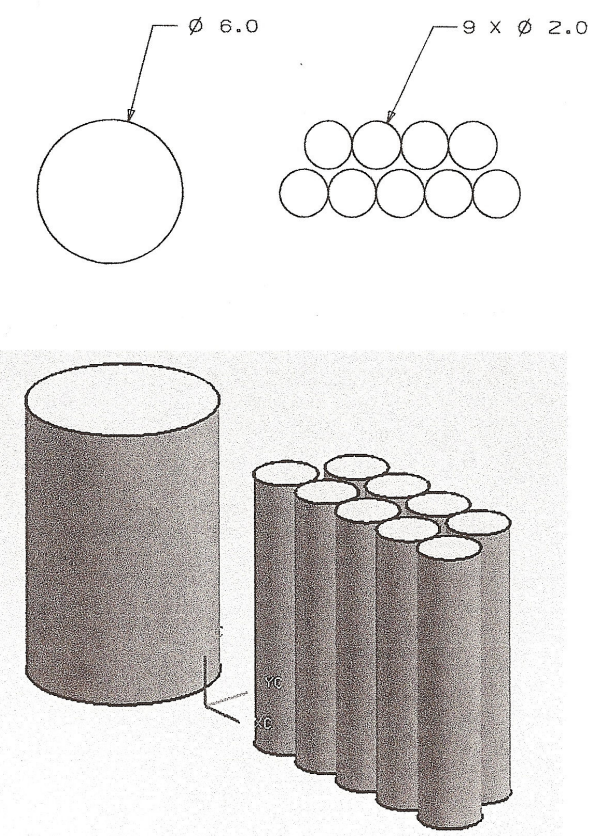

Figure 1. Cylinders used to illustrate differences in specific surface area

surface area of the smaller cylinders is 1:2.5. This hypothetical case shows that the smaller cylinders with $1 / 3$ the diameter of the larger cylinder has 2.5 times the specific surface area of the larger cylinder. Therefore, with more specific surface area smaller fibers would have the propensity for greater interactions with the polymer matrix than larger fibers. These interactions could result in higher transfer of applied stress or load between the composite constituents. 
Another variable that makes PCNs attractive relative to traditional composites is the aspect ratio of nanofillers, which Kiney et al. ${ }^{8}$ suggest range from 1 to 10,000 while those of traditional fillers range from 1 to 50. The impact of aspect ratio on the modulus of elasticity of composites is shown in Figure 2 using the Halpin-Tsai ${ }^{9}$ equation [1] for predicting the longitudinal moduli of aligned short-fiber composites. Figure 2 shows that the modulus of elasticity of composites increases with increasing aspect ratio of fillers.

$$
\frac{E_{l}}{E_{m}}=\frac{1+(2 l / d) \eta_{l} V_{f}}{1-\eta_{l} V_{f}}
$$

where $E_{c}=$ longitudinal modulus of elasticity of composite

$E_{m}=$ longitudinal modulus of elasticity of matrix

$l / d=$ fiber/filler aspect ratio

$V_{f}=$ fiber/filler volume fraction

$E_{f}=$ modulus of elasticity of fiber/filler

$$
\eta_{l}=\frac{\left(E_{f} / E_{m}\right)-1}{\left(E_{f} / E_{m}\right)+2(l / d)}
$$

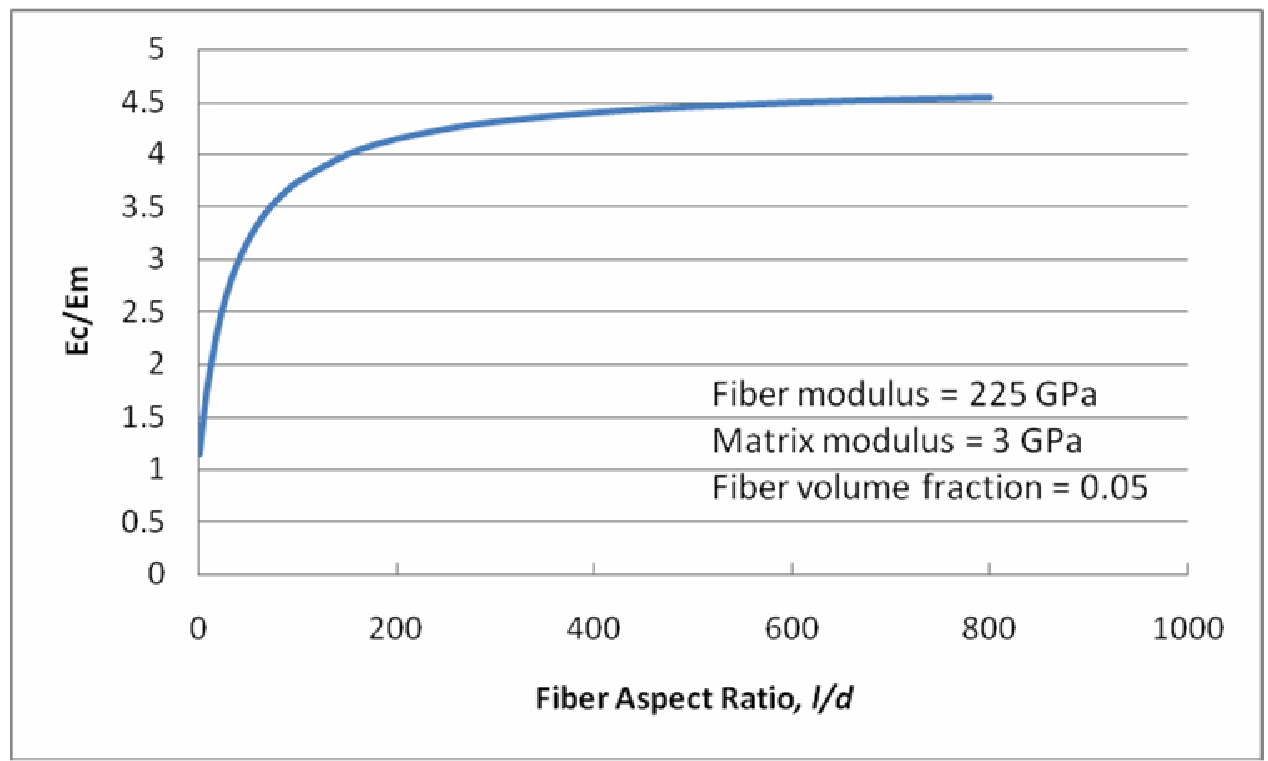

Figure 2. Effect of fiber aspect ratio on the modulus of elasticity

The Manufacturing Engineering Technology Program at Ball State University. 
The Manufacturing Engineering Technology (MET) program was created from a Manufacturing Technology program in 1993 and was accredited by the Association Board for Engineering and Technology (ABET) in 1995. Presently, the MET curriculum offers three courses in plastics. These courses are

- ITMFG 225 - Industrial Plastics - a sophomore level course

- ITMFG 325 - Plastics Product Design - a junior level course

- ITMFG 326 - Plastics Production Systems - a junior level course

ITMFG 225, which is the first course in the sequence of plastics courses offered in the Department of Technology at Ball State University, is an overview of the plastics industry covering topics such as plastic materials, additives, processing techniques, and waste management. In ITMFG 326, injection molding, extrusion, blown film, and thermoforming are examined in greater detail than in ITMFG 225. Therefore topics such mold design, die design, screw design, effects of process variables on product quality, and safety issues are covered. In ITMFG 325, plastic materials and properties are emphasized. Topics covered include rheological properties of plastics, American Society for Materials and Testing standards (for example, ASTM D-1238, D-638, D-256), thermoplastics, thermosets, and composites. It is in ITMFG 325 that materials on polymer-clay nanocomposites are covered. The topics covered include the information described in the introduction section of this paper, the methods of incorporating the clay nanoparticles into the polymer matrix, namely, polymerization and extrusion melt blend methods. It is emphasized that the goal of both methods is to achieve complete dispersion of clay nanoparticles, which exist in layers/stacks, in the polymer matrix if the benefits of PCNs are to be realized. Figure 3 is used to illustrate an ideal situation where the clay nanoparticles are dispersed completely in the polymer matrix.

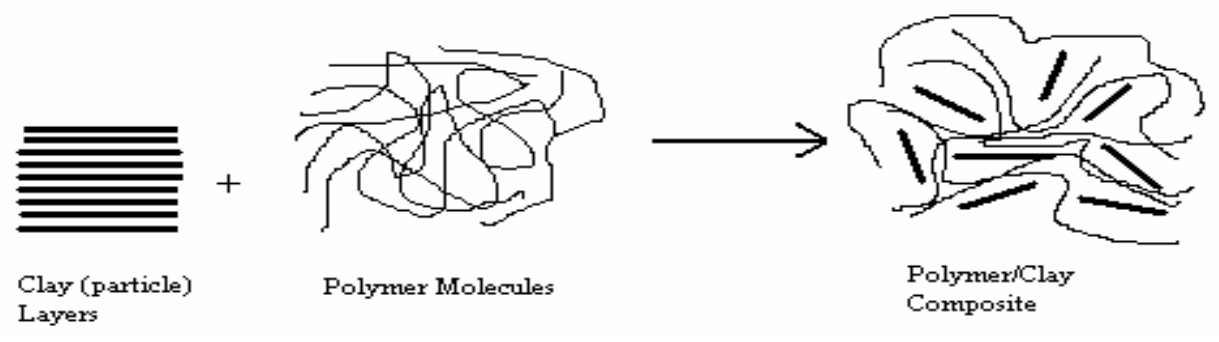

Figure 3. An illustration of clay nanoparticles dispersed in polymer matrix.

The method of conveying this information to the students is through lecture presentations supplemented by handouts from trade journals. As part of the course requirement, put in place to reinforce the students' understanding of PCNs, the students are required to do experimental research projects based on information covered in class. The findings of these projects are presented to the class, and the presentations are graded. It was observed by the author that these projects encourage students to take active participation in their learning experience at Ball State University. Also, it was observed that students 
did not see the projects as impossible tasks if they were allowed to work in teams and if each project was broken into discrete steps. These steps are

- Choose a topic

- Conduct literature search of the topic

- Write a research proposal

- Procure materials, if proposal was accepted

- Conduct experiments, collect data, and analyze data

- Present findings

- Submit a written report

The following studies are examples of research projects undertaken by students in MET

- Effects of Weld Lines on the Tensile Strength of Injection Molded Glass-Filled Polypropylene at Different Processing Temperatures by Jason Huff, Jimmy Ayres, and Jared Korpal.

- An Analysis of the Effects of Regrind Generations on the Mechanical Properties of Injection-Molded Glass-Fiber Reinforced Polypropylene by Thomas J. Fisher and Andrew Slightom.

- The Effects of Blue Organic Pigment on the Tensile Strength of Injection-Molded Polypropylene by Ian Vaughan and Dennis Weldishofer.

- An Investigation of Tensile Modulus, Tensile Strength, and Flame Resistance of Nylon 66 - Clay Nanocomposites by Matt Tracy and Chris Whelchel.

\section{Experimental}

Following the approval of their research proposal, Matt Tracy and Chris Whelchel sought and contacted appropriate vendors for the materials required for their study. They obtained Nylon 66 (Polyamide Wellamid® 22L-N) from Wellman, Inc. and clay nanoparticles (Nanomer 1.34 TCN Nanoclay) from Nanocor®. The clay nanoparticles were incorporated into the Nylon 66 with a Brabender twin screw extruder at $6 \mathrm{wt} \%$ loading. Before the blending process by the extruder, Nylon 66 resins and clay nanoparticles were mixed thoroughly in a five gallon bucket for about 10 minutes. Figure 4 shows plastics resins coated with clay nanoparticles before the melt blending process.

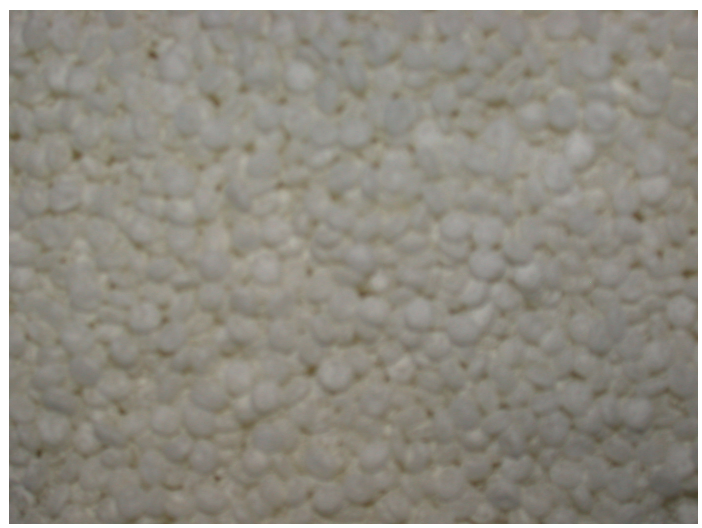

Figure 4. Plastics resins coated with clay nanoparticles. 
The extruder temperature profile for the blending process was

- $487^{\circ} \mathrm{F}$ for zone 1

- $468^{\circ} \mathrm{F}$ for zone 2

- $432^{\circ} \mathrm{F}$ for zone 3

The twin screw extruder was fitted with a die for making strands. Thus, PCN exited the die as strands, which were pulled through a water cooling trough, air dried and pelletized with a Killion pelletizer. The pellets obtained by this process were dried with a dehumidifying dryer at $347^{\circ} \mathrm{F}$ for 4 hours. The dried PCN pellets were feed into a Sandretto 60 Ton injection molding machine to produce the ASTM standard tensile specimens. The injection molding temperature profile was

- $560^{\circ} \mathrm{F}$ for the nozzle

- $540^{\circ} \mathrm{F}$ for the front zone of the barrel

- $550^{\circ} \mathrm{F}$ for the middle zone of the barrel

- $560^{\circ} \mathrm{F}$ for the rear zone of the barrel

- $200^{\circ} \mathrm{F}$ for the mold

and injection pressure profile was

- 800 psi for injection pressure

- 500 psi for packing pressure

- 500 psi for hold pressure

An Instron 1011 Tensile Testing machine was used to determine the tensile modulus and tensile strength @ break of nylon 66 - clay nanocomposite according to ASTM D-638. Underwriters Laboratory (UL) flame rating - UL94 method was used for the flame resistance test. All test specimens were conditioned according to ASTM D- 618 before testing.

\section{Results}

Table I shows the average tensile properties of five test specimens of the nylon 66 - clay nanocomposite (PCN). These results showed some improvement in the tensile modulus and strength of the PCN as has been suggested by Densult et $\mathrm{al}^{10}$.

Table I. Tensile properties of Nylon 66 - Clay Nanocomposites (PCN)

\begin{tabular}{|c|c|c|c|}
\hline $\begin{array}{c}\text { Tensile } \\
\text { Property }\end{array}$ & $\begin{array}{c}\text { Nylon 66 } \\
\text { (control) }\end{array}$ & $\begin{array}{c}\text { Nylon 66 - } \\
\text { Clay } \\
\text { Nanocomposite }\end{array}$ & Difference \\
\hline $\begin{array}{c}\text { Tensile } \\
\text { Strength @ } \\
\text { break (psi) }\end{array}$ & $6865 \pm 283$ & $8165 \pm 610$ & $19 \%$ \\
\hline $\begin{array}{c}\text { Tensile Strain } \\
\text { @ break (in) }\end{array}$ & $1.69 \pm 0.43$ & $0.13 \pm 0.01$ & $-92 \%$ \\
\hline $\begin{array}{c}\text { Tensile } \\
\text { Modulus of } \\
\text { Elasticity (psi) }\end{array}$ & $43053 \pm 1288$ & $62862 \pm 3669$ & $46 \%$ \\
\hline
\end{tabular}


While the tensile properties of the PCN behaved as expected, the result of its flame resistance test was worrying because the PCN did not demonstrate any flame retarding tendencies when compared to the neat Nylon 66 as shown in Figure 6 and 7, respectively. The reason for this behavior was not clear even after several attempts by the students to contact Nanocor. The students were rather disappointed by the result of the flame test of the PCN because the result was contrary to the claims in the literature ${ }^{2-4,7}$.

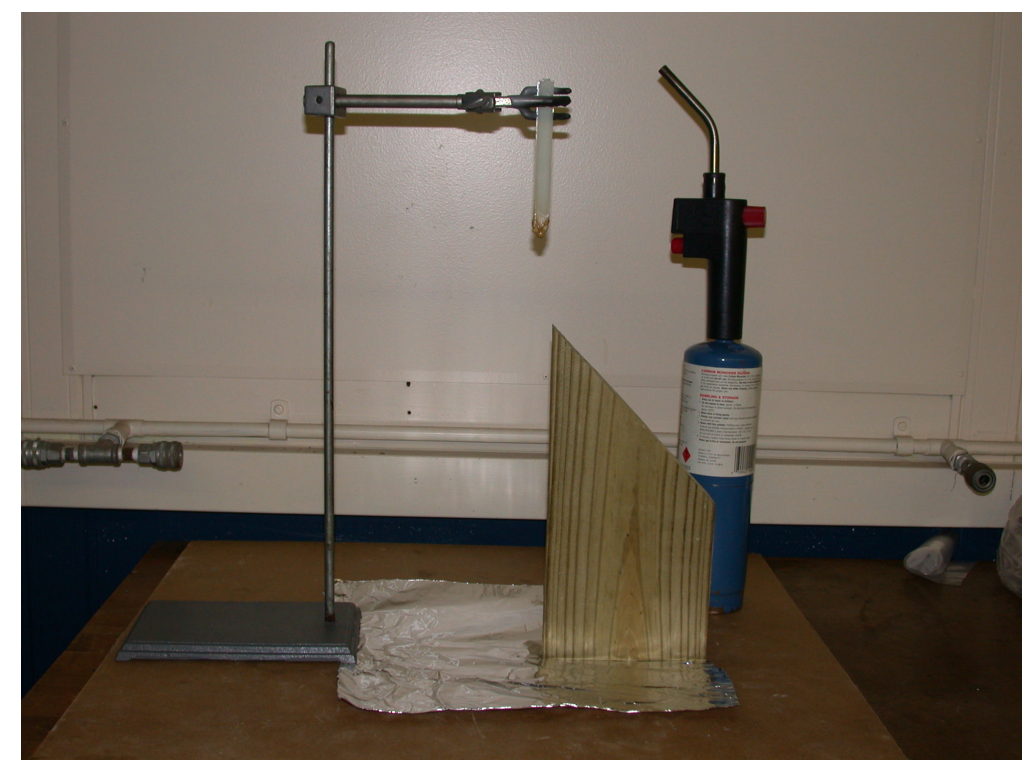

Figure 5. Flame resistance test set-up

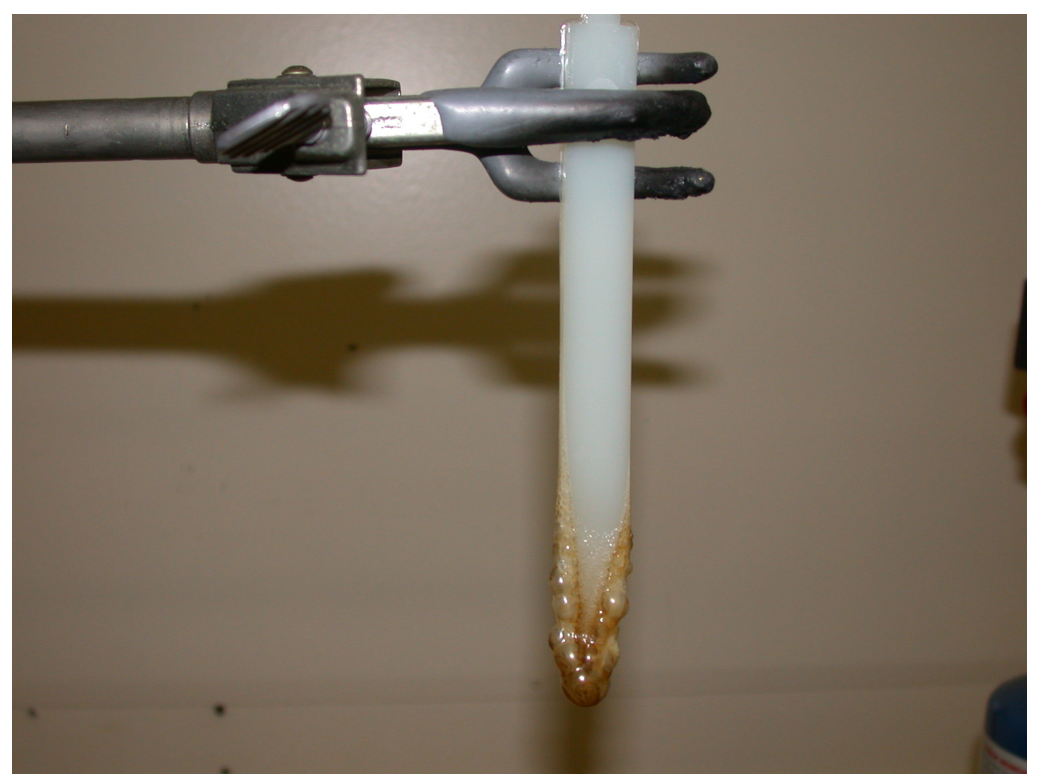

Figure 6. Flame resistance test of the neat Nylon 66 


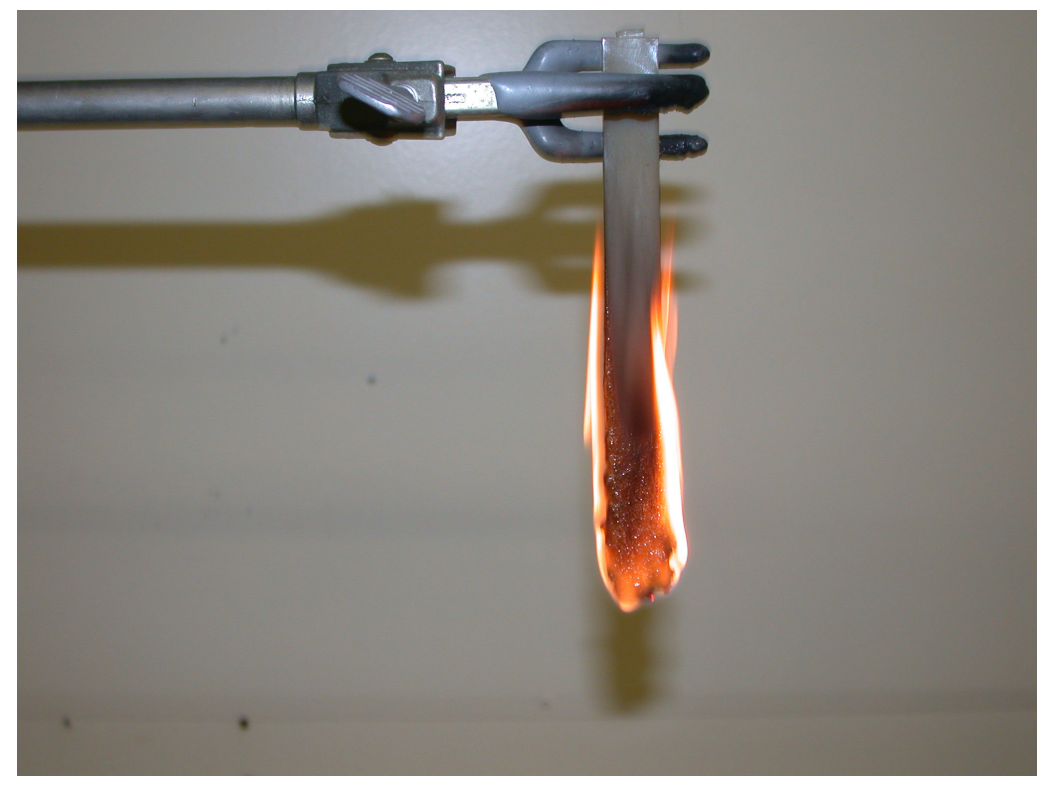

Figure 7. Flame resistance test of the Nylon 66 - Clay Nanocomposite (PCN)

\section{Conclusion}

The approach used to introduce polymer-clay nanocomposites to students of the manufacturing engineering technology program at Ball State Univeristy seems to be effective because it encouraged the students to combine classroom information with materials from refereed journals in an attempt to have a good understanding of novel materials such as PCNs. The appreciation of the nature these materials were further reinforced by the experiments done to elucidate their unique properties. Another outcome of these research projects was the skills gained in planning, organizing, and conducting experiments with classmates to successfully complete the projects.

Perhaps another method of assessing the success of this approach could be the performance of MET majors in the Society of Manufacturing Engineers certified manufacturing technologist exams taken before and after the introduction of polymer-clay nanocomposites to the program. The students' performance in the composites section of the exam in 2005 (before the introduction of PCNs to the program) was a $67 \%$ pass rate while in 2006 (the year PCNs was introduced) the pass rate was $83 \%$; the national average pass rate for the same composite section of the exam was $62.2 \%{ }^{11}$.

A further indication of the success of the program was the award of $\$ 1,000.00$ in 2006 by the Office the Dean of the College of Applied Science and Technology to support an undergraduate student interested in working with polymer-clay nanocomposites.

\section{Bibliography}

1. Okada, A., Usuki, A., Twenty Year of Poymer-Clay Nanocomposites, Macromolecular Materials Engineering, 2006, 291, 1449-1476. 
2. Treece, M.A., Zhang, W., Moffitt, R.D., Oberhauser, J.P., Twin-Screw Extrusion of Polypropylene-Clay Nanocomposites: Influence of Masterbatch Processing Screw Rotation Mode, and Sequence, Polymer Engineering and Science, 2007, 47(6), 898-911.

3. Rao, Y., Pochan, J.M., Mechanics of Polymer-Clay Nanocomposites, Macromolecules, 2007, 40, 290-296.

4. Zhang, Q., Wang, K., Men, Y., Fu, Q., Dispersion and Tensile Behavior of Polypropylene/Montmorillonite Nanocomposites Produced via Melt Intercalation, Chinese Journal of Polymer Science, 2003, 21 (3), 359-367.

5. Hull D., Clyne, T.W., An Introduction to Composite Materials, $2^{\text {nd }}$ Edition, 1996, Cambridge University Press, UK, page 1.

6. Agwarwal, B.D., Broutman, L.J., Analysis and Performance of Fiber Composites, $2^{\text {nd }}$ Edition, 1990, John Wiley and Sons, Inc, New York, USA, page 2.

7. Dasari, A., Lim, S-H., Yu, Z-Z., Mai, Y-M., Toughening, Thermal Stability, Flame Retardancy, and ScratchWear Resistance of Polymer-Clay Nanocomposites, Australian Journal of Chemistry, 2007, 60(7), 496-518.

8. Winey, K.I., Vaia, R.A., Polymer Nanocomposites, MRS Bulletin, 2007, 32(4), 314-322.

9. Agwarwal, B.D., Broutman, L.J., Analysis and Performance of Fiber Composites, $2^{\text {nd }}$ Edition, 1990, John Wiley and Sons, Inc, New York, USA, page 129-130.

10. Denault, J., Bureau, M.N., Cole, K.C., Ton-That, M.-T., Microstructure and Performance of Injection Molded Polyamide 6/Clay Nanocomposite and its Glass Fiber Composite. 500-509.

11. Neff, G., American Society for Engineering Education (ASEE), 2003 IL/IN Sectional Conference, April 4-5, Valparaiso University, Valparaiso, IN, 2003, page 4. 